\title{
Refractive surgery training during residency - do not be afraid of the dark
}

This article was published in the following Dove Press journal:

Clinical Ophthalmology

19 November 2014

Number of times this article has been viewed

Kepa Balparda'

Ana María Díaz ${ }^{2}$

Ana María Londoño 3

'Department of Ophthalmology, Universidad Pontificia Bolivariana, ${ }^{2}$ Psychiatry Research Group, Universidad de Antioquia, ${ }^{3}$ School of Medicine, Universidad Pontificia Bolivariana, Medellín, Colombia
Correspondence: Kepa Balparda Department of Ophthalmology, Universidad Pontificia Bolivariana, Medellín, Antioquia, Colombia Tel +5744936304 Email kb@kepabalparda.com
Abstract: Refractive errors are a fairly common eye condition worldwide, and the ophthalmologist should be capable of offering the patient both nonsurgical and surgical solutions to their refractive conditions. Nevertheless, currently, refractive surgery training during residency is poor at best. This paper explores recent evidence to suggest that postsurgical results of patients operated on by residents are not inferior to those operated on by experienced staff. It points out the urgent need to improve the current approach to refractive surgery training.

Keywords: refractive surgical procedures, refractive errors, education

\section{Refractive surgery training during residency}

Refractive errors are definitively the most common eye condition worldwide. ${ }^{1}$ From a theoretical point of view, presbyopia has a prevalence of $100 \%$ in older subjects, although because of previous refractive characteristics, not all patients get to notice this disorder in their daily lives. Also, recent studies have shown that the worldwide prevalence of myopia is about $50 \%,{ }^{2}$ while clinically significant hyperopia affects about $6 \%$ of the population. ${ }^{3}$ Additionally, there is an important body of evidence about the deterioration in quality of life and side costs directly and indirectly due to these refractive conditions. ${ }^{4}$ Although they should not be considered as "diseases" by themselves (rather, they should be taken as "conditions" that are amenable to a certain correction to improve the quality of the eye behavior), they are an extremely important aspect of the ophthalmologist's day-to-day work.

Due to these factors, it is clear that the ophthalmologist should be able to offer the patient with refractive errors effective solutions to their visual quality problems, in order to improve their quality of life. Although a large proportion of individuals with refractive errors can (and are) treated with glasses or contact lenses, there is a group of patients who desire and are candidates for a surgical solution. Among these surgical options, we can find the interventions that are performed on the corneal surface and those that require an intraocular approach, such as phakic ${ }^{5}$ and pseudophakic lenses.

Ophthalmology residency programs should provide the students with an adequate preparation not only in clinical aspects but also in surgical skills to treat the most common eye diseases. It is obvious that this should include the handling of ametropic conditions due to their high prevalence. It is also obvious that as with any surgery, preoperative assessment is extremely important, probably even more so than the actual surgical procedure itself. Nowadays, most residents receive comprehensive and meaningful training in preoperative assessment for refractive surgery. However, actual surgical technique training for the correction of ametropias during residence is at best poor, not only in Colombia but also in other countries. This is explained 
by multiple factors, such as the nature of the patients who undergo this type of surgery and the role of health insurers in their payment.

To explain this, it may be useful to make a parallel between refractive surgery and the most regularly performed eye surgery worldwide: phacoemulsification with intraocular lens implantation for the treatment of functionally significant cataract. Patients with cataracts (except in special cases, such as posttraumatic cataracts) tend to be senile patients, with an average age of $72.9^{6}$ to 73.9 years. ${ }^{7}$ Additionally, it has been found that up to $25.6 \%$ of patients undergoing phacoemulsification have some type of ocular morbidity, while $12.3 \%$ have a preoperative condition that requires complex surgery. ${ }^{7}$ In contrast, patients undergoing refractive surgery tend to be significantly younger subjects, with a mean age of $24.6^{8}$ to 33.0 years. ${ }^{9}$ Additionally, these patients usually have no detectable ocular or systemic findings, and in them a substantial visual gain would be expected. Finally, we cannot ignore the fact that these surgeries could be considered "aesthetic", so health insurance companies do not need to cover these procedures financially, and the patient should be the one to pay for them. All of the aforementioned points combine to create extremely high visual expectations after surgery, both by the patient and their family, and also by the surgeon.

Taking this into account, it does not seem surprising to note a certain resilience of ophthalmology professors to allow their residents to participate as first surgeons in their refractive surgery cases. In fact, it is an attitude that is completely understandable, due to the fact that we are taking into consideration the vision of a young patient who has high expectations and who is paying for the surgery, and leaving him in the hands of an inexperienced resident who (probably) is just starting their learning curve.

However, as already mentioned, a residency program in ophthalmology should ideally give the student the tools to face the most common eye problems, including, obviously, ametropias. With this in mind, training in refractive surgery should be an absolute obligation for all training programs in the specialty.

Currently, there is not a study assessing the state of training in refractive surgery in Colombia or in Latin America. However, there is interesting information gleaned from the study of Kwon et $\mathrm{al}^{10}$ who sent a survey to coordinators and directors of 113 ophthalmology residency programs in the US, trying to gather information about training in refractive surgery in each of their respective institutions. Of the programs that responded to the survey, about half $(54.2 \%)$ allowed their residents to carry out at least one refractive surgery during their training, the majority of these $(92.3 \%)$ during their third year of residency. The residents performed an average of 4.4 refractive surgeries (range 1-10) before their graduation as ophthalmologists. This number is interesting, considering that currently the Accreditation Council for Graduate Medical Education requires that in the US, a resident should act as a principal surgeon or as an assistant in at least six keratorefractive surgeries before their graduation as an ophthalmologist. As Weber et al mentioned, ${ }^{11}$ this new requirement takes into account the growing prominence of refractive surgery in the practice of ophthalmology.

Taking this situation into account, there are two focal points on the table: to know whether or not it is appropriate to offer a patient the option of having an aesthetic surgery performed by a surgeon in training, and how to get their approval.

Regarding the first point, there are a number of studies that have evaluated the postoperative visual results of keratorefractive surgeries performed by residents. In 2005 , LeBoyer et $\mathrm{al}^{12}$ evaluated a total of 44 eyes of 22 subjects who had undergone myopic laser-assisted in situ keratomileusis (LASIK) performed by residents, finding that on the first postoperative day, $58 \%$ of subjects had an uncorrected vision equal to or better than 20/25. Furthermore, when the patients were evaluated 9 months after surgery (which could be considered as the "definite vision" after surgery), 77\% had an uncorrected vision equal to or better than 20/25. At both evaluations, all evaluated patients had an uncorrected vision of $20 / 40$ or better. It is also noted that the retreatment rate was $6.8 \%$, similar to rates reported for experienced surgeons, which are between $4.7 \%$ and $37.9 \% .^{12}$

However, the researchers in the previous study did not compare their results against experienced surgeons, so its scope remains limited. In this regard, two recent studies are interesting, as both of them had a control group for comparison of variables. Weber et al published the largest of them ${ }^{11}$ in 2012, where the postoperative results of 333 eyes operated on by residents were compared to 977 eyes operated on by experienced surgeons. These authors found that 6 months after the intervention, $96.1 \%$ and $94.6 \%$ of eyes operated on by residents and highly specialized surgeons, respectively, had an uncorrected visual acuity equal to or better than $20 / 20$ ( $P=0.324)$. Also, after the same time of evaluation, it was found that $94.0 \%$ of eyes operated on by residents and $91.1 \%$ by highly specialized surgeons were within $\pm 0.50 \mathrm{D}$ of emmetropia $(P=0.105)$. Not even when patients undergoing LASIK were analyzed exclusively (a more complex 
surgical technique than photorefractive keratectomy) could the authors find a statistically significant difference in the final uncorrected vision of patients. Neither a higher rate of complications nor need for retreatment was found. A subsequent study by Shtein et a ${ }^{13}$ focused only on LASIK performed with a femtosecond laser, finding similar visual results to those described earlier. Nevertheless, this group did find a slightly increased risk of microstriae and debris at the interface in the group of residents. Neither complication affected the postoperative vision quality of patients.

The second focal point (perhaps the most complex of them) is how to provide an opportunity for the resident to perform the surgery per se. The unique intraoperative characteristics of keratorefractive surgery do not allow for an easy opportunity for the resident to perform the surgery without the patient readily noticing it, a technique regularly used in surgical training in Colombia.

Recent evidence and reasoning seem to indicate that the best option would be to be completely open and honest with the patient, giving them the opportunity to undergo surgery with a resident with the patient's full knowledge. Clearly, a significant number of patients (if not all of them) would tend to refuse initially; nevertheless, there do seem to be ways of making this offer somewhat more "attractive". Definitively, the most used and successful option for accomplishing this in the American system is to provide a significant economic discount if the patient allows the resident to perform the surgery. This approach has been so successful that in the US, only $2 \%$ of programs do not offer such a discount, while $66 \%$ of programs offer a discount of over $50 \%$ of the regular price of the surgery. Obviously, a clear and honest explanation about the importance of training and surgical exposure during residency will help the patient to assimilate in a better way the proposal of participation of the resident as first surgeon.

Another point to take into account would be the postoperative following of the patients operated on by physicians when they were residents, but who at the time have already graduated. It would probably be an issue sometimes, as the patients would probably have to be shunted to a different resident. It would be the responsibility of every residency program to create a way of dealing appropriately with this issue, such as taking into consideration the patient's opinion on whether they would like to keep their follow-up with the original surgeon or with a new resident.

Definitely, refractive surgery training during residency remains a challenge, because of its unique features within the surgical arsenal of ophthalmology, mainly due to unique patient characteristics. However, as mentioned, this type of surgical exposure is absolutely necessary if we intend to train an ophthalmologist who will be able to deal with the majority of the eye problems of the population. There is already substantial evidence indicating that the postoperative results achieved by residents (both in terms of visual acuity and in terms of complication rate) are statistically equal to those achieved by very experienced surgeons. Therefore, professors should not be wary of letting residents act as first surgeons in well-selected cases (and preferably with total acceptance by the patient). Each training program must have a method to assess the relevance of this training within its own population, and to strive for the best way to expose the residents to this type of surgical situations, which will result in better professional growth and eventually in a better approach to patients with ocular pathologies.

\section{Acknowledgment}

The authors wish to thank Professor Carlos Restrepo Peláez, MD (Department of Ophthalmology, Hospital Pablo Tobón Uribe) for teaching them the art and craft of hands-on refractive surgery training. This article is dedicated to him.

\section{Disclosure}

The authors report no conflicts of interest in this work.

\section{References}

1. Hyman L. Myopic and hyperopic refractive error in adults: an overview. Ophthalmic Epidemiol. 2007;14(4):192-197.

2. Rahi JS, Cumberland PM, Peckham CS. Myopia over the lifecourse: prevalence and early life influences in the 1958 British birth cohort Ophthalmology. 2011;118(5):797-804.

3. Pan CW, Klein BE, Cotch MF, et al. Racial variations in the prevalence of refractive errors in the United States: the multi-ethnic study of atherosclerosis. Am J Ophthalmol. 2013;155(6):1129-1138.e1.

4. Ieong A, Hau SC, Rubin GS, Allan BD. Quality of life in high myopia before and after implantable Collamer lens implantation. Ophthalmology. 2010;117(12):2295-2300.

5. Hassaballa MA, Macky TA. Phakic intraocular lenses outcomes and complications: Artisan vs Visian ICL. Eye (Lond). 2011;25(10): $1365-1370$.

6. Lum F, Schein O, Schachat AP, Abbott RL, Hoskins HD Jr, Steinberg EP. Initial two years of experience with the AAO National Eyecare Outcomes Network (NEON) cataract surgery database. Ophthalmology. 2000;107(4):691-697.

7. Lundström M, Barry P, Henry Y, Rosen P, Stenevi U. Visual outcome of cataract surgery; study from the European Registry of Quality Outcomes for Cataract and Refractive Surgery. J Cataract Refract Surg. 2013;39(5):673-679.

8. Yang Y, Du C, Sheng Y, et al. Preoperative characteristics of patients undergoing LASIK in 1997 versus 2004 at one surgical eye center in China. J Refract Surg. 2006;22(7):703-707.

9. Yuen LH, Chan WK, Koh J, Mehta JS, Tan DT. A 10-year prospective audit of LASIK outcomes for myopia in 37,932 eyes at a single institution in Asia. Ophthalmology. 2010;117(6):1236-1244.e1.

10. Kwon RO, Shah VA, Krishna R, Hausheer J. Resident laser in situ keratomileusis surgical training in United States residency programs. J Cataract Refract Surg. 2009;35(9):1629-1632. 
11. Weber ML, Stutzman RD, Mines MJ, et al. Residency training in refractive surgery. J Cataract Refract Surg. 2012;38(11):1962-1969.

12. LeBoyer RM, Deutsch TA, Rubenstein JB. Results of residentperformed laser in situ keratomileusis. J Cataract Refract Surg. 2005;31(4):771-775.
13. Shtein RM, Michelotti MM, Kaplan A, Mian SI. Association of surgeon experience with outcomes of femtosecond LASIK. Ophthalmic Surg Lasers Imaging. 2012;43(6):489-494.

\section{Publish your work in this journal}

Clinical Ophthalmology is an international, peer-reviewed journal covering all subspecialties within ophthalmology. Key topics include: Optometry; Visual science; Pharmacology and drug therapy in eye diseases; Basic Sciences; Primary and Secondary eye care; Patient Safety and Quality of Care Improvements. This journal is indexed on

\section{Dovepress}

PubMed Central and CAS, and is the official journal of The Society of Clinical Ophthalmology (SCO). The manuscript management system is completely online and includes a very quick and fair peer-review system, which is all easy to use. Visit http://www.dovepress.com/ testimonials.php to read real quotes from published authors. 